\title{
Effects of Social Network on Health Education
}

\author{
Pragya Maharjan, Student \\ Kathmandu Shiksha Campus
}

\begin{abstract}
Social networks have become an inseparable part of our modern life. Social network, if used properly, can be very beneficial for all the users in every aspect. There are many researched applications of Social network in different fields, its application in Health Education was not mentioned anywhere properly, though. For the survey, the students of Bachelors'levels, majoring in Health and Physical Education in constituent and affiliated colleges of T.U. of Kathmandu Valley were selected from the different colleges. Altogether 171 student, who were acquainted with Social network, were selected as respondents for the study. Questionnaires were used to collect quantitative data and interview guidelines were used to obtain qualitative data from teachers.

The students and teachers profoundly used Social network still they should use it for educational purpose. The communication gap between teachers and students were clearly perceived.
\end{abstract}

Keywords: Social networks, Facebook, Twitter, LinkedIn, YouTube, Instagram, etc.

\section{Introduction}

Social network is an internet-based unique blend of communication activities that integrate social interaction and technology, with the essence of words, pictures, audio, and videos. Over billions of people from all over the world use social networking to make connections and share information. Use of social network on a personal level is limited to communicating with friends and family, learn new things, developing new hobbies and to achieve entertainment. On a professional level, it is done for broadening work-related knowledge horizon and helping to build a professional network by connecting with similar professionals (University of South Florida, 2017).

Nations (2017) terms social network as web-based communication tools that facilitate people to interact with each other by sharing and consuming information. The popular social networks used by numerous people include Facebook, Twitter, Pinterest, Google+, LinkedIn, YouTube, Instagram, snap chat, Reddit, Myspace, etc. The main features of social network are user accounts, profile pages, friends, followers and groups, newsfeeds, like buttons, notifications and a review button. Any sites containing these features are social networks (Nations, 2017). 
As said by Marshall McLuhan, a philosopher of communication theory, "The new electronic independence re-creates the world in the image of a global village." This electronic independence totally depends on the (Karadkar, 2015). The year 1997 is considered as the birth year of social network. In 2004, Mark Zuckerberg launched Facebook, which is the number one Social network website today and it currently boasts over 2.2 billion monthly active users (Hale, 2015).

Social network fosters new ideas and information as well as raise awareness of contemporary events and issues. Students can collaborate with their peers or friends on assignments and projects on many online media platforms. On the other hand, evidence suggests that use of Social network can cause insomnia, distraction, cyberbullying, hacking and mental disorders and anxiety attacks along with physical harms. Teachinglearning activities through Social network can be a good alternative to the traditional lecture format (Chassiakos, Radesky, Christakis, Moreno, \& Cross, 2016). Thus, learning is more effective when we just focus on the task of learning and avoid the temptation of distractions" (Cruz, 2017).

As per the survey conducted by Pew Research Centre, about 72 percent of high school and 78 percent of college students spend time on social networking sites like Facebook, Twitter, Instagram (Gazette Alive, 2017). However, Shachak (2017) points that the adoption of Social network in health science education is very much lower. Social network has countless implications in health science and education (Shachak, 2017).

Social networks, apart from being an integral part of life, have turned to an essential component of any business strategy. The health industry is already using Social network to change how it works, whether through public health campaigns or virtual doctor's visits on Skype. Social network has been responsible for relevant changes in both personal and community health, especially by making it easier for large numbers of people to rapidly share information. From Facebook's Safety Check - which allows users in disaster zones to mark themselves as safe (Guzman \& Vis, 2016)?

The easy availability and accessibility of smart phones and mobile networks, growing ISP's has significantly made the Social network users higher by the year 2017. The most used Social network sites by Nepalese are Facebook with the total accounts of 6,400,000 (including more than one account of one person). Among these, 893620 number users are of age group eighteen to twenty-four, followed by the age group twenty-five to thirty-four. Among these users, 69 percent are male whereas 31 percent are female (Facebook, 2017). Twitter is another Social network site which as a whole comes at $12^{\text {th }}$ position in terms of most visited sites. There are approximately 1 million users in Nepal (Twitter, 2017). 
In case of Nepal, the internet penetration rate increased from three times within these five years i.e. from 20 percent to 63 percent (Timilsina, 2018). The increment in internet penetration rate definitely leads to increment in Social network outreach of people. The maximum numbers of Social network users are of age group 18-24 (Becker, 2015). And, this age group is generally of the students studying in bachelor level, I chose bachelor third year's students, studying health education for the study. These age groups are the ones who use smartphones on regular basis and access Social network apps from mobiles. The study objectives are to identify the status of using social network and practice and effect of social network in teaching health education.

\section{Methodology}

The study followed the mixed method, i.e., quantitative and qualitative. The quantitative data were collected from students whereas qualitative data were collected from teachers.

A questionnaire was used to collect the data from students while interview guidelines were used to collect data from teachers. Teachers teaching Health and Physical education (HPE) and students studying HPE in B. Ed. $3^{\text {rd }}$ year in Kathmandu valley were the population of the study. The number of students studying Bachelors in Health and Physical Education, third year, in T.U. constituent and affiliated campuses from Kathmandu valley is 316 . The sample size is calculated from using Raosoft online calculator in 5 percent margin error and 95 percent confidence level. The sample size was calculated as 171 from the online calculator. Questions for questionnaire were prepared to collect data from students whereas interview guidelines were prepared for in-depth interview with teachers to collect qualitative data. The questionnaire contains close ended questions to find the status, practice and impact of Social network to students. Similarly, the interview guidelines contain the outline regarding the status, practice and effect of Social network in teaching health education.

For the collection of data, the researcher personally visited. For interview, appointments were taken before. Then interview was taken using the interview guidelines.

The respondent students were asked if their teachers tag, share, post or message educational stuffs to them. About 60 percent ( 57.8) respondents said that their teachers share, tag and message them on relevant posts.

When the same question was asked to the teachers, if they post, tag, share or message relevant educational posts to their students, some teachers said yes and some said no.

One of the teachers (Id1) said:

"I always make sure that I share relevant posts and tag my students on it.

The main use of Social network is that people should share, tag and show the information they have to others. Hence, it is a very important thing." 
Another teacher (Id2) said

"When I see some relevant posts or videos, instead of tagging and sharing,

I prefer to show it in the class."

Hence, we can conclude that teachers use Social network and tag and post or message the relevant contents to their students.

The students were asked if they search or post their study related problems and topics in Social network. More than 90 (90.40) percent students said yes and only 9.60 percent said no. This shows that the students seek help from Social network for their study related problems.

The students were asked if they find proper solutions to their problems through Social network. More than 60 (63.30) percent students said they find their proper solutions in Social network, 15.7 percent said they sometimes find their solutions and 21.10 percent said they do not find their proper solutions in Social network.

As per OCT of Skinner, finding proper solutions to their problems acts as the stimulus in this case. More the students find their desired solutions, more they are motivated to post and search for the new topics and get knowledge of it. Hence, with increase in finding proper solutions, students tend to search more relevant things, thus learning new things and ideas.

The students were asked if having free data packages from mobile companies to access educational Social network would be beneficial for students. Majority of the students i.e. 78.3 percent said yes and 21.70 percent said no. The same question was asked to the teachers and they all agreed that having free data packages from mobile companies to access educational Social network is beneficial for students. The free data packages also works as a stimulus and people tend to use more Social network and get benefit educationally.

The students were asked if they think getting health related information in Nepali language would be helpful. Majority of the respondent students i.e. 57.8 percent agreed on it, 37.3 percent were unsure and only 4.8 percent think it wouldn't benefit.

The same question was asked to the respondent teachers during qualitative data collections. Almost all the teachers, except two agreed that contents in Nepali would be very beneficial for the students.

One of the two teachers (Id3) who disagreed on the statement said

"I don't think having contents in Nepali would be of any benefit. It's not

about what language you read; it is about how you search and which 
content you read. They are bachelor level students. It's fine if they don't have a good command over professional English, but in my view, they should understand and they should be able to search and find the things related to their study. After all, they are asked questions in English in their board exam."

The other teacher (Id4) said

"Content in Nepali might be helpful for students, but a student who can surf internet and use Social network must understand the contents in English. Also, the contents in English are more authentic, if the sites or pages which share the contents are authentic. In case of Nepali contents, there is either copied and translated contents which are unauthentic. "

One of the teachers (Id1) who agreed on having Nepali contents would be beneficial said

"Health education related contents in Nepali would help the students of all levels to get the desired information. In many times, even when I search for the contents, I get confused with the professional English language. Some people/websites prefer using contents/words which are hard to understand by normal users. This might cause ambiguity and health education is a very crucial subject. If any of the information you get is misleading or misinterpreted, the whole scenario changes. Hence, it is very important to have contents in Nepali for everyone to understand."

The other teacher (Id2) said

"Educating in mother tongue is definitely helpful for students. There are very few Nepali websites and posts which provide authentic data and posts. It is difficult to trust the contents in Nepali, whereas, there are plenty of other sites which provide contents from trustable sources. Also, most of the Nepali contents are rarely updated and cited properly. "

This shows that majority of students and teachers agree on the fact that having health education related contents in Nepali would be beneficial for the students to learn better. But few of them disagreed to this fact.

Getting knowledge in mother tongue is definitely beneficial, but English being a universal language, sharing knowledge in English would be beneficial. As per Margaryan and Littlejohn (2008), sharing knowledge with people from different sides of globe enables new forms of collaboration and knowledge sharing for learners. Furthermore, they add, this enhances transferring knowledge between various contexts, e.g. online and offline realities or local and global networks (Margaryan \& Littlejohn, 2008).

From above data, we can say that, it is important to have contents in mother tongue if the contents might be difficult to understand or ambiguous. But sharing knowledge would be beneficial if used a universal language. 


\section{Conclusion}

The students and teachers profoundly use Social network. The study groups and circles were created by many students and teachers which make the teaching and learning through Social network easier. Though most of the students and teachers are already benefited from Social network, still there are numerous students who are using Social network just to connect with friends and family and for entertainment purpose. If teachers and students are trained on proper use of Social network, the maximum benefit from Social network can be taken in teaching health education.

\section{References}

Chassiakos, R., Radesky, J., Christakis, D., Moreno, A., \& Cross, C. (2016). Children and Adolescents and Digital Media. Chicago: Council on communications and media.

Cruz, D. J. (2017). Social media impacts students socially, academically. Retrieved from Logos light: http://www.niacc.edu/logoslite/2016/11/10/social-media-impacts-studentssocially-academically/

eMarketer. (2016, June 30). Nearly one-third of the world will use social networks regularly this year. Retrieved from eMarketer: https://www.emarketer.com/Article/Nearly-OneThird-of-World-Will-Use-Social-Networks-Regularly-This-Year/1014157

Facebook. (2017, February 14). Facebook ad manager . Retrieved from Facebook: https://www. facebook.com/ads/manage/powereditor/creation?act $=47963041$

Gazette Alive. (2017, June 24). Effect and impact of social platform on youth. Retrieved from Gazette Alive Blogs: http://www.akhtarbari.com/blog/effect-of-social-platform-onstudents/

Guzman, A., \& Vis, F. (2016, April 7). 6 ways social media is changing the world. Retrieved from We Forum: https://www.weforum.org/agenda/2016/04/6-ways-social-media-ischanging-the-world

Hale, B. (2015, June 16). The history of social media: social networking evolution. Retrieved from History Cooperative: http://historycooperative.org/the-history-of-social-media/

Karadkar, A. (2015, September 13). The impact of social media on student life. Retrieved from Technician Online: http://www.technicianonline.com/opinion/article_d1142b70-5a9211e5-86b4-cb7c98a6e45f.html

Nations, D. (2017, May 30). What is social media? Explaining the big trend. Retrieved from Lifewire: https://www.lifewire.com/what-is-social-media-explaining-the-bigtrend-3486616

Shabir, G. (2014). The impact of social media on youth: a case study of bahawalpur city. Bahawalpur: Asian journal of social sciences \& humanities.

Shachak, A. (2017). Social media in health science education: an international survey. Toronto: JMIR Publications Inc.

Timilsina, V.(2018,February27).Increaseininternetpenetrationratebythreetimes. Retrieved from Kantipur Daily: https://www.kantipurdaily.com/business/2018/02/27/20180227082417. html 